\title{
Enhancement of toxin- and virus-neutralizing capacity of single-domain antibody fragments by $N$-glycosylation
}

\author{
M. M. Harmsen • C. B. van Solt • H. P. D. Fijten
}

Received: 20 March 2009/Revised: 29 April 2009 / Accepted: 29 April 2009 / Published online: 12 May 2009

(C) The Author(s) 2009. This article is published with open access at Springerlink.com

\begin{abstract}
Single-domain antibody fragments (VHHs) have several beneficial properties as compared to conventional antibody fragments. However, their small size complicates their toxin- and virus-neutralizing capacity. We isolated 27 VHHs binding Escherichia coli heat-labile toxin and expressed these in Saccharomyces cerevisiae. The most potent neutralizing VHH (LT109) was $N$-glycosylated, resulting in a large increase in molecular mass. This suggests that $N$-glycosylation of LT109 improves its neutralizing capacity. Indeed, deglycosylation of LT109 decreased its neutralizing capacity three- to fivefold. We also studied the effect of glycosylation of two previously isolated VHHs on their ability to neutralize foot-and-mouth disease virus. For this purpose, these VHHs that lacked potential $\mathrm{N}$ glycosylation sites were genetically fused to another VHH that was known to be glycosylated. The resulting fusion proteins were also $\mathrm{N}$-glycosylated. They neutralized the virus at at least fourfold-lower VHH concentrations as compared to the single, non-glycosylated VHHs and at at least 50-fold-lower VHH concentrations as compared to their deglycosylated counterparts. Thus, we have shown that $\mathrm{N}$-glycosylation of VHHs contributes to toxin- and virus-neutralizing capacity.
\end{abstract}

Keywords Nanobody Recombinant antibody . Neutralization $\cdot N$-glycosylation $\cdot$ Yeast

M. M. Harmsen $(\bowtie) \cdot$ C. B. van Solt $\cdot$ H. P. D. Fijten

Central Veterinary Institute of Wageningen UR,

P.O. Box 65, 8200 AB Lelystad, The Netherlands

e-mail: michiel.harmsen@wur.nl

\section{Introduction}

Camelids produce antibodies that are naturally devoid of light chains (Hamers-Casterman et al. 1993). The single Nterminal domains of these heavy-chain antibodies (VHHs) are fully capable of antigen binding. They have several advantages for biotechnological purposes, such as a high physicochemical stability, a high production level in microorganisms, and the facile construction of genetic fusions of two VHH domains (Harmsen and De Haard 2007). As a result, there is currently much interest in various therapeutic applications of VHHs (Harmsen and De Haard 2007; Saerens et al. 2008).

The mechanism of action of therapeutic antibody fragments is often based on blocking the interaction of their cognate antigen with a specific receptor. This is exemplified by antibodies neutralizing heat-labile toxin (LT), which is secreted by enterotoxigenic E. coli, and the closely related cholera toxin (CT), produced by Vibrio cholerae. Both toxins (reviewed by Spangler 1992) cause diarrheal diseases and belong to the AB5 toxin family. The five Bsubunits are responsible for holotoxin binding to the monosialoganglioside (GM1) receptor on intestinal epithelial cells (Cuatrecasas 1973) after which the single A subunit is injected into the cells (Holmgren 1981). Neutralizing antibodies generally bind to the B-subunit and block receptor interaction (Apter et al. 1993). Similarly, virus neutralization by antibodies predominantly relies on the ability to block the interaction between the virion and a specific cellular receptor (Parren and Burton 2001). Such blocking may occur due to direct binding to a viral epitope involved with receptor interaction. Consistent with this we observed that most potent foot-and-mouth disease virus (FMDV) neutralizing VHHs recognized an epitope called the GH-loop (Harmsen et al. 2007), which binds to the 
cellular receptor. Alternatively, binding of a bulky antibody close to a site involved with receptor interaction may also prevent receptor interaction, a process called steric hindrance (Mateu and Verdaguer 2004).

Due to their small size, VHHs are probably less well suited for steric hindrance. Increasing the size of VHHs by $\mathrm{N}$-glycosylation could increase their neutralizing capacity. $\mathrm{N}$ glycosylation occurs at Asn-X-Ser/Thr sequons, where X represents any amino acid except Pro. About $90 \%$ of such sites become $N$-glycosylated (Gavel and von Heijne 1990). About $10 \%$ of the VHHs have such potential $\mathrm{N}$-glycosylation sites (Harmsen et al. 2000). $N$-glycosylation is a complex sequential process involving the transfer of a coreoligosaccharide to the protein within the endoplasmic reticulum and the addition of an outer-chain oligosaccharide within the Golgi apparatus. In mammals, the type of outerchain glycosylation is highly variable between different proteins and sites and can be classified into high-mannose, hybrid, and complex-type glycosylation. Baker's yeast $(S$. cerevisiae) only adds outer chains consisting of $\alpha 1-3$ - and $\alpha 1-6$-linked mannose residues. Depending on the particular glycosylation site, such yeast outer-chain glycosylation can result either in relatively short chains of about $10 \mathrm{kDa}$ (corelike $N$-glycosylation) or very long chains with different lengths (high-mannose-type $\mathrm{N}$-glycosylation) that have a molecular mass of 50-100 kDa (Kukuruzinska and Lennon 1998). As a result, yeast $N$-glycosylation of small proteins such as VHHs that have an average size of $15 \mathrm{kDa}$, can result in a large increase in molecular mass.

We therefore analyzed the contribution of $N$-glycosylation of VHHs to their neutralizing capacity. We isolated several LT-binding VHHs and produced them by secretory yeast expression. A potent LT-neutralizing VHH was found to be $N$-glycosylated. We have further shown that its glycosylation contributes to its neutralization. We also showed that we could increase the FMDV-neutralizing capacity of two non-glycosylated VHHs by genetic fusion to another VHH that is glycosylated. The possible mechanism by which $\mathrm{N}$-glycosylation improves neutralization capacity of VHHs is discussed.

\section{Materials and methods}

Strains and genetic constructs

E. coli XL1-Blue (Stratagene, La Jolla, CA) was used for routine recombinant DNA manipulation. E. coli TG1 (Stratagene) was used for phage display purposes. $S$. cerevisiae SU51 (YT6-2-1L) MATa; can1; his4-519; leu2$3,-112 \mathrm{Cir}^{+}$, which is a $\mathrm{cir}^{+}$derivative of AH22 (ATCC 38626), was used for $\mathrm{VHH}$ production as described previously (Van der Vaart 2002).
Phage display selection of LT-binding VHHs

The basic procedure for selection of antigen specific VHHs from immunized llamas by phage display using vector pUR4676 has been described before (Frenken et al. 2000; Harmsen et al. 2002). We immunized a single llama with $100 \mu \mathrm{g}$ LT (Sigma, Saint Louis, MO) per immunization. Phage display selections of clones producing LT-binding VHHs were performed by biopanning (McCafferty and Johnson 1996), using polystyrene 96-well plates coated with 0.1 or $0.01 \mu \mathrm{g} / \mathrm{ml}$ LT (Sigma). The VHH encoding regions of clones binding LT in ELISA were subjected to automated DNA sequencing as described previously (Harmsen et al. 2000). The deduced VHH amino acid sequences were aligned according to the IMGT system (Lefranc 2004) for alignment, numbering, and complementarity-determining region (CDR) definition of immunoglobulins. Additional gaps had to be introduced at the end of CDR2 to accommodate VHHs with unusually long CDR2s.

\section{Yeast production of VHHs}

LT-binding VHHs containing a C-terminal hexahistidine tag were produced by secretory yeast expression using plasmid pUR4584 and yeast strain SU51 (Harmsen et al. 2005b). For this purpose, VHH clones were transferred from pUR4676 to pUR4584 using the PstI and BstEII restriction sites. Single FMDV-binding VHHs M180 and M200 and the porcine immunoglobulin G binding VHH VI-12 were produced as described previously using vector pUR4585 (Harmsen et al. 2007) with C-terminal c-myc and hexahistidine tags. The VHH2s M180shVI-12 and M200shVI-12 were produced as described previously (Harmsen et al. 2005a), but using the llama short-hinge sequence without cysteines (amino acid sequence AHHSEDPSSKSP) instead of the synthetic Gly-Gly-Ser linker for fusion of the two VHH domains. Secreted VHHs or VHH2s were purified by immobilized-metal affinity chromatography as described previously (Harmsen et al. 2005b). VHHs were deglycosylated by $16 \mathrm{~h}$ incubation of $5 \mathrm{mg} / \mathrm{ml} \mathrm{VHH}$ with $2 \mathrm{U} / \mathrm{ml}$ endoglycosidase $\mathrm{H}$ (Roche Applied Science, Mannheim, Germany) at $37^{\circ} \mathrm{C}$ in $50 \mathrm{mM}$ sodium citrate, $\mathrm{pH}$ 5.5.

Vero cell assay

The cytopathogenic effect (CPE) of LT on African green monkey kidney (Vero) cells was used to measure LT toxicity (Speirs et al. 1977). Monolayers of Vero cells were grown in Minimal Essential Medium Eagles with Earle's salts and L-glutamine (EMEM; Invitrogen, San Diego, CA) and containing $10 \%$ normal calf serum in $96-$ well plates at $37{ }^{\circ} \mathrm{C}$ in a $5 \% \mathrm{CO}_{2}$ atmosphere. The ability of VHHs to 
neutralize LT toxicity was determined by preincubating $100 \mu \mathrm{l} 1 \mu \mathrm{g} / \mathrm{L}$ LT in Medium 199 without serum (Invitrogen) with a twofold dilution series of $10 \mathrm{mg} / \mathrm{L}$ VHH for $1 \mathrm{~h}$ at $37^{\circ} \mathrm{C}$. These mixtures were then transferred to the Vero cell monolayers. After a further 24-h incubation at $37{ }^{\circ} \mathrm{C}$ in a $5 \% \mathrm{CO}_{2}$ atmosphere, the percentage of cells showing a CPE was microscopically determined. The $\mathrm{VHH}$ concentration required to inhibit the $\mathrm{CPE}$ on $75 \%$ of the cells was then determined.

\section{ELISAs}

GM1, LT, CT, and the CT subunits A (CTA) and B (CTB) were all obtained from Sigma. For all ELISAs, high-binding polystyrene 96-well plates (Greiner, Solingen, Germany) were coated overnight at $4{ }^{\circ} \mathrm{C}$ with proteins in $50 \mathrm{mM}$ carbonate/bicarbonate buffer, $\mathrm{pH}$ 9.6. LT was biotinylated using aminohexanoyl-biotin- $N$-hydroxysuccinimide (Zymed, San Francisco, CA) at a protein to biotin ratio of 100 on a weight basis.

The ability of VHHs to bind LT or CT holotoxins or their subunits was determined by incubation of plates coated with $1 \mathrm{mg} / \mathrm{L}$ of these antigens with twofold dilution series of $10 \mathrm{mg} / \mathrm{L} \mathrm{VHH}$ in ELISA-buffer $(1 \%$ skimmed milk; 0.05\% Tween-20; $0.5 \mathrm{M} \mathrm{NaCl} ; 2.7 \mathrm{mM} \mathrm{KCl} ; 2.8 \mathrm{mM}$ $\mathrm{KH}_{2} \mathrm{PO}_{4} ; 8.1 \mathrm{mM} \mathrm{Na} \mathrm{HPO}_{4} ; \mathrm{pH}$ 7.4). Bound VHH was detected with peroxidase-conjugated polyclonal rabbit immunoglobulins anti-llama-immunoglobulin (Frenken et al. 2000) and staining with 3,3',5,5' tetramethylbenzidine (TMB). The $\mathrm{VHH}$ concentration resulting in an extinction at $450 \mathrm{~nm}$ of 0.3 was then determined by nonlinear regression analysis.

The ability of anti-LT VHHs to inhibit binding of LT to GM1 was determined using an inhibition ELISA. Serial twofold dilution series of $10 \mathrm{mg} / \mathrm{L} \mathrm{VHH}$ were preincubated with $0.1 \mathrm{mg} / \mathrm{L}$ biotinylated LT in $100 \mu \mathrm{l}$ PBS containing $1 \%$ ovalbumin (Sigma; grade V) and $0.05 \%$ Tween-20 for $1 \mathrm{~h}$ at room temperature. These mixtures were then transferred to a plate coated with $0.2 \mathrm{mg} / \mathrm{L}$ GM1 and incubated for another hour. Bound biotinylated LT was then detected using peroxidase-conjugated streptavidin (Jackson Immunoresearch, West Grove, PA) and staining with TMB. The $50 \%$ inhibitory concentration $\left(\mathrm{IC}_{50}\right)$ was calculated by interpolating the $\mathrm{VHH}$ concentration resulting in $50 \%$ of the extinction value obtained by a control incubation without VHH.

\section{SDS-PAGE}

VHHs $(1 \mu \mathrm{g})$ were subjected to reducing SDS-PAGE, using precast gels (Novex, San Diego, CA), and stained using Sypro Orange and a STORM fosfor imager (Molecular Dynamics, Sunnyvale, CA).
In vitro FMDV neutralization assay

VHH concentrations required for neutralization of FMDV $\mathrm{O}_{1}$ Manisa were determined as described previously (Harmsen et al. 2007) using 20 tissue culture infective doses required to infect $50 \%$ of the wells $\left(\mathrm{TCID}_{50}\right)$ in duplicate assays using monolayers of secondary swine kidney cells and serial twofold dilutions of $10 \mathrm{mg} / \mathrm{ml}$ VHHs. When using endoglycosidase-H-treated $\mathrm{VHH}(2) \mathrm{s}$,

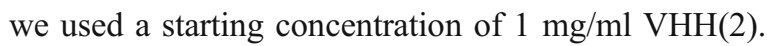

Nucleotide sequence accession numbers

Nucleotide sequences of selected anti-LT VHHs were submitted to the EMBL database under accession numbers AJ849409-AJ849413, AJ849415-AJ849427, AJ849431AJ849438 and AJ849442 (Fig. 1).

\section{Results}

\section{Isolation of LT-binding VHHs}

We isolated 180 clones producing VHHs that bound LT in ELISA by phage display selection from an immunized llama. After fingerprinting and sequence analysis, we obtained 27 unique VHHs (Fig. 1). Antibody variable domains, including VHHs, contain three complementaritydetermining regions (CDRs) that are often directly involved in antigen binding (Muyldermans et al. 2001). CDR3 generally is most variable (Harmsen et al. 2000). Many of the 27 clones had similar CDR3 sequences, allowing the dissection into 11 CDR3 groups (A-K, Fig. 1).

\section{Antigenic specificity of LT-binding VHHs}

The 27 unique VHHs were expressed in yeast and purified. The $\mathrm{VHH}$ concentration required to inhibit $75 \%$ $\left(\mathrm{IC}_{75}\right)$ of the toxic effect of LT in a Vero cell assay ranges from more than $10 \mathrm{mg} / \mathrm{L}$ for non-neutralizing clones to 0.0017 for clone LT109 (Table 1). Most neutralizing clones also inhibited binding of LT to its cellular receptor GM1, as determined by ELISA. Clone LT109 again had the lowest $\mathrm{IC}_{50}$ (Table 1). The subunit specificity of LTbinding VHHs was determined using the commercially available subunits of the related CT. Most clones crossreacted sufficiently to $\mathrm{CT}$ holotoxin to enable such determination (Table 1). These VHHs required a similar $\mathrm{VHH}$ concentration for binding to the $\mathrm{CT}$ B-subunit and holotoxin, suggesting that they bind the B-subunit. The subunit specificity of LT104 and LT139 could not be determined due to insufficient cross reaction with $\mathrm{CT}$ (Table 1). 


\begin{tabular}{|c|c|c|c|c|c|c|}
\hline & $\mathrm{CDR} 3$ & $\begin{array}{l}\text { EMBL } \\
\text { Accession }\end{array}$ & & & & \\
\hline Clone & Group & Number & & CDR1-IMGT & & CDR2-IMGT \\
\hline LT105 & A & AJ849412 & $\ldots D \ldots P$ & .S.L. & $. A . Y \ldots . .$. & $S R \cdot S P$ \\
\hline LT106 & B & AJ849413 & $\ldots \ldots$ & . S F G Y . G G & $\ldots$. . . . $\ldots$ & S D L S A. \\
\hline LT109 & $\mathrm{c}$ & AJ849415 & $\ldots \ldots$ & $\mid \cdot F \ldots D D . A$ & $I \ldots \ldots \ldots$ I S & . V G. D N Y T . \\
\hline LT128 & D & AJ849419 & $\ldots \ldots P$ & . I N S R...R & $\mathrm{T} \ldots \mathrm{Y} \ldots \mathrm{N} Q \ldots \mathrm{L} \ldots \mathrm{R}$ & $. S D G . S T$. \\
\hline LT131 & E & AJ849422 & $\ldots \ldots s$ & R T I $\ldots$ L H A & $\ldots Y \ldots \mathrm{L} \ldots \mathrm{T}$ & . . A. T T. \\
\hline LT132 & $\mathrm{F}$ & AJ849423 & $\ldots \ldots$ D. . & - RA.T- -- & $\mathrm{vA}_{\ldots \ldots} \ldots \ldots$ s $\mathrm{s}$ & .RWI.S.T. \\
\hline LT141 & G & 849426 & . & . T.V.SN . & $\mid . \mathrm{D} \cdot \mathrm{H} \ldots \mathrm{K} \ldots \mathrm{L} \cdot \mathrm{R}$ & . S. GDVL. \\
\hline LT143 & $\mathrm{H}$ & AJ849427 & $\ldots \ldots$ & . I I,$R F N A$ & $\ldots Y \ldots \mathrm{Y} \ldots Q \ldots \mathrm{G}$ & . SSG.TTI... \\
\hline 101 & $\mathrm{I}$ & AJ849409 & $\cdots \cdots$ & $A S \ldots V, N P$ & $\mid R \cdot Y \cdots Q \cdot L \cdot G$ & $\ldots \mathrm{FN} \ldots \mathrm{T} \ldots$ \\
\hline LT104 & I & AJ849411 & $\ldots \ldots \ldots \ldots$ & $A S \ldots V \cdot N P$ & $\ldots Y \ldots Y_{1} \ldots \mathrm{L}$ & $\ldots \mathrm{FN} \ldots \mathrm{T} \ldots$ \\
\hline LT111 & $\mathrm{I}$ & AJ849416 & $\ldots \ldots \ldots \ldots$ & $A S \ldots V \cdot N P$ & 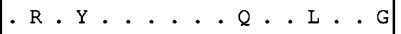 & $\ldots \mathrm{FN} \ldots \mathrm{T} \ldots$ \\
\hline LT116 & $\mathrm{I}$ & AJ849417 & . . & $A S \ldots V . N P$ & 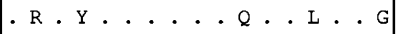 & $\ldots \mathrm{FN} \ldots \mathrm{T} \ldots$ \\
\hline LT133 & $\mathrm{I}$ & AJ849424 & 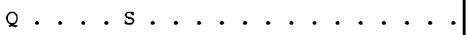 & A S . . V . N P & $|. R \cdot Y \ldots \ldots, \ldots, G|$ & $\ldots \mathrm{FN} \ldots \mathrm{T} \ldots$ \\
\hline LT129 & I & AJ849420 & $\mathrm{a} \ldots \ldots \ldots \ldots$ &. $\mathrm{N} \cdot \mathrm{V} \cdot \mathrm{NP}$ & $\ldots Y \ldots Y_{1} \ldots \mathrm{L}$ & $\mathrm{V} \cdot \mathrm{FT} \cdot \mathrm{T} T \cdot$. \\
\hline LT139 & I & AJ849425 & $\ldots \ldots \ldots$ & $A N \ldots V L N$ & 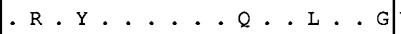 & $V . F I . T T \ldots$ \\
\hline LT103 & $\mathrm{J}$ & AJ849410 & $\ldots \ldots \ldots \ldots \ldots$ & $\ldots \ldots$ & $\ldots \ldots \ldots \ldots$ & $\ldots \ldots$. . W K GAMT \\
\hline LT124 & $\mathrm{J}$ & AJ849418 & . & $\ldots s \ldots$ & $\ldots \ldots \ldots \ldots$ & . S..AI.WKGAST. \\
\hline LT130 & $\mathrm{J}$ & AJ849421 & $\ldots \ldots$ & . A... & $\ldots \ldots$ & $\ldots \ldots \mathrm{GN}$ W K GAL T. \\
\hline LT154 & $\mathrm{J}$ & AJ849431 & $Q \ldots \ldots \mathrm{N} \ldots \mathrm{T}$ & ...N.W & $\ldots$ & $\ldots A R$. WNGAMT. \\
\hline LT155 & $\mathrm{J}$ & AJ849432 & $\ldots \ldots \ldots$ & .D.E.V V & $\ldots \ldots \ldots$ & $\ldots \ldots$. RASGGMT \\
\hline LT156 & $\mathrm{u}$ & AJ849433 & $\ldots \ldots \ldots$ & $.0 \ldots$ & $I \ldots \ldots \ldots \ldots$ & $\ldots$ A I N W $\mathbf{S} G G Q T$ \\
\hline LT161 & J & AJ849434 & $\ldots \ldots$ & $\ldots \ldots$ & $F \ldots \ldots \ldots \ldots$ & $\ldots$. . DI K K S SA. \\
\hline LT163 & $\mathrm{u}$ & AJ849435 & $\ldots \ldots$. . . . & $\ldots \mathrm{D} \ldots$ & $\ldots \ldots \ldots$ & M... A M N W K G A L T. \\
\hline LT165 & $\mathrm{u}$ & AJ849436 & & $\ldots \mathrm{E} \ldots \mathrm{V}$ & A....V V & $\ldots \ldots$ T T G A M T \\
\hline LT176 & $\mathrm{J}$ & AJ849442 & $\ldots \ldots \mathrm{N} \ldots \mathrm{T}$ & $\ldots \ldots$ & $\ldots \ldots$ & . S..AD.WNGAMT \\
\hline LT168 & $\mathrm{K}$ & 849437 & & . FSSDD. & A. $\mathrm{SC}$ & . . S.DG.T. . \\
\hline LT170 & $\mathrm{K}$ & AJ849438 & $\ldots \ldots \ldots$ & . FSSDD. & I $A \ldots \ldots A$ A $\ldots$ & . . S.DG.T. \\
\hline & & & ESGGGLVQAGGSLRLSCAA & G G T F S I Y T & $M G W F R Q A P G K E R E F \vee A A$ & I T R S G A S - - \\
\hline & & & 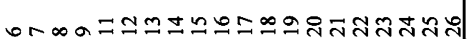 & 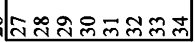 & 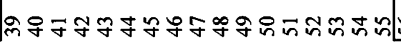 & $n \ln$ \\
\hline
\end{tabular}

\begin{tabular}{l} 
Clone \\
LT105 \\
LT106 \\
LT109 \\
LT128 \\
LT131 \\
LT132 \\
LT141 \\
LT143 \\
\hline LT101 \\
LT104 \\
LT111 \\
LT116 \\
LT133 \\
LT129 \\
LT139 \\
\hline LT103 \\
LT124 \\
LT130 \\
LT154 \\
LT155 \\
LT156 \\
LT161 \\
LT163 \\
LT165 \\
LT176 \\
\hline LT168 \\
LT170 \\
\hline Consensus
\end{tabular}

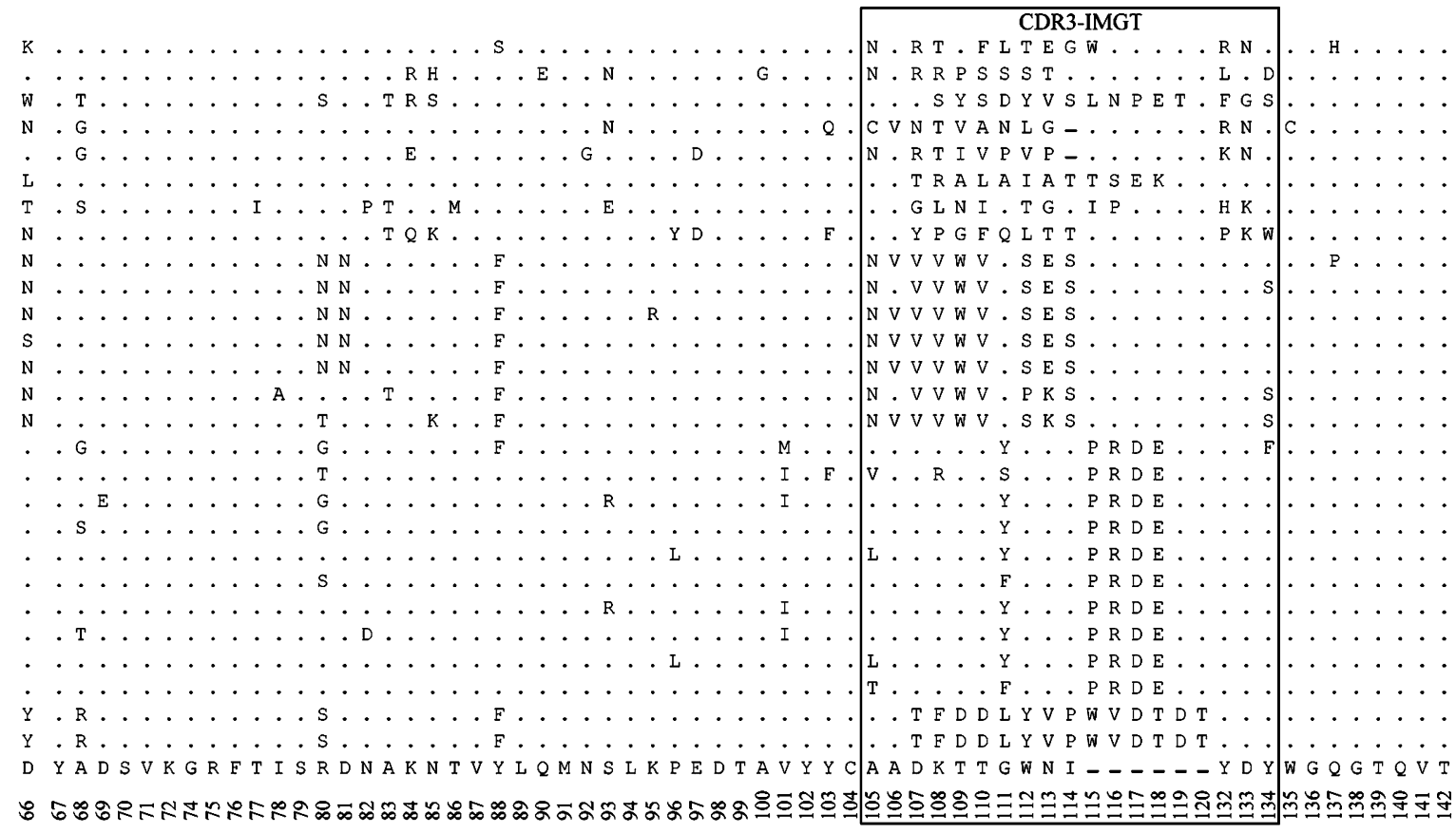

Fig. 1 Multiple amino acid sequence alignment of E. coli LT-binding VHHs. Dashes indicate gaps introduced for sequence alignment. Dots indicate amino acids identical to the consensus sequence. Residue numbering and CDR definitions are according to the IMGT numbering system (Lefranc 2004). Residues 1-5 (amino acid

\section{Effect of VHH $N$-glycosylation on LT neutralization}

The VHHs LT109 and LT156 have potential $N$-glycosylation sites at IMGT positions 61 and 62, respectively, which are sequence QVQLQ) and 143-145 (amino acid sequence VSS) are not shown since they are vector-encoded. The VHH clones are ranked according to CDR3-group and clone number. VHHs of the same CDR3 group are boxed. Potential $N$-glycosylation sites are indicated in boldface

both located in CDR2 (Fig. 1). SDS-PAGE analysis showed that LT109 indeed consisted of a heterogeneous highmolecular-weight species, indicative of high-mannose type $\mathrm{N}$-glycosylation, in addition to a minor amount of a discrete 
Table 1 Toxin neutralization and antigenic specificity of LTbinding VHHs
${ }^{\text {a }} \mathrm{SD}$, standard deviation

${ }^{b}>10$, the VHH showed no effect at the highest concentration analyzed $(10 \mathrm{mg} / \mathrm{L})$

c endoH, sample that was deglycosylated by endoglycosidase $\mathrm{H}$ treatment

${ }^{\mathrm{d}} \mathrm{ND}$, not determined

\begin{tabular}{|c|c|c|c|c|c|c|c|c|}
\hline \multirow{3}{*}{$\begin{array}{l}\text { Clone } \\
\text { LT105 }\end{array}$} & \multirow{2}{*}{\multicolumn{2}{|c|}{$\frac{\text { Vero cell assay } \mathrm{IC}_{75}}{\text { Mean } \pm \mathrm{SD}^{\mathrm{a}}(\mathrm{mg} / \mathrm{L})}$}} & \multirow{2}{*}{\multicolumn{2}{|c|}{$\frac{\text { GM1-LT ELISA } \mathrm{IC}_{50}}{\text { Mean } \pm \mathrm{SD}(\mathrm{mg} / \mathrm{L})}$}} & \multicolumn{4}{|c|}{ Titer in ELISA $(\mathrm{mg} / \mathrm{L})$} \\
\hline & & & & & \multirow{2}{*}{$\frac{\mathrm{LT}}{0.073}$} & \multirow{2}{*}{$\frac{\mathrm{CT}}{1.3}$} & \multirow{2}{*}{$\frac{\text { CTB }}{0.26}$} & \multirow{2}{*}{$\frac{\text { CTA }}{>10}$} \\
\hline & $>10^{\mathrm{b}}$ & \pm 0 & $>10$ & \pm 0 & & & & \\
\hline LT106 & 3.3 & \pm 0 & 0.028 & \pm 0.003 & 0.032 & 0.25 & 0.12 & $>10$ \\
\hline LT109 & 0.0017 & \pm 0.0012 & 0.021 & \pm 0.008 & 0.18 & 0.12 & 0.15 & $>10$ \\
\hline LT109 endoH ${ }^{c}$ & 0.0084 & \pm 0.005 & 0.06 & \pm 0.024 & $\mathrm{ND}^{\mathrm{d}}$ & ND & ND & ND \\
\hline LT128 & $>10$ & \pm 0 & $>10$ & \pm 0 & 0.002 & 0.098 & 0.027 & $>10$ \\
\hline LT131 & 6.7 & \pm 4.7 & $>10$ & \pm 0 & 0.023 & 0.023 & 0.012 & $>10$ \\
\hline LT132 & $>10$ & \pm 0 & $>10$ & \pm 0 & 0.020 & 0.024 & 0.013 & $>10$ \\
\hline LT141 & 3.3 & \pm 0 & $>10$ & \pm 0 & 0.038 & 0.019 & 0.016 & $>10$ \\
\hline LT143 & $>10$ & \pm 0 & $>10$ & \pm 0 & 0.028 & 0.040 & 0.016 & $>10$ \\
\hline LT101 & $>10$ & \pm 0 & 0.91 & \pm 0.34 & 0.042 & 4.6 & 1.6 & $>10$ \\
\hline LT104 & $>10$ & \pm 0 & 7.2 & \pm 4.9 & 0.010 & $>10$ & 8.6 & $>10$ \\
\hline LT111 & 1.1 & \pm 0 & 0.67 & \pm 0.26 & 0.042 & 3.1 & 0.83 & $>10$ \\
\hline LT116 & $>10$ & \pm 0 & 1.5 & \pm 1.4 & 0.010 & 0.66 & 0.21 & $>10$ \\
\hline LT133 & $>10$ & \pm 0 & 8.5 & \pm 6.4 & 0.059 & 4.1 & 1.6 & $>10$ \\
\hline LT129 & 0.21 & \pm 0.23 & 0.81 & \pm 0.14 & 0.20 & 3.6 & 2.9 & $>10$ \\
\hline LT139 & $>10$ & \pm 0 & 0.18 & \pm 0.11 & 0.059 & 8.1 & $>10$ & $>10$ \\
\hline LT103 & 0.74 & \pm 0.52 & 0.86 & \pm 0.29 & 0.16 & 0.13 & 0.071 & $>10$ \\
\hline LT124 & 0.12 & \pm 0 & 0.27 & \pm 0.11 & 0.054 & 0.037 & 0.033 & $>10$ \\
\hline LT130 & 0.21 & \pm 0.23 & 0.78 & \pm 0.01 & 0.035 & 0.032 & 0.023 & $>10$ \\
\hline LT154 & 0.39 & \pm 0.03 & 0.96 & \pm 1.02 & 0.048 & 0.022 & 0.016 & $>10$ \\
\hline LT155 & 0.02 & \pm 0.009 & 0.21 & \pm 0.25 & 0.028 & 0.014 & 0.010 & $>10$ \\
\hline LT156 & 0.17 & \pm 0.06 & 2.1 & \pm 2.5 & 0.024 & 0.019 & 0.010 & $>10$ \\
\hline LT161 & 0.27 & \pm 0.21 & 2.9 & \pm 3.6 & 0.20 & 0.061 & 0.026 & $>10$ \\
\hline LT163 & 0.07 & \pm 0.05 & 0.18 & \pm 0.03 & 0.038 & 0.026 & 0.024 & $>10$ \\
\hline LT165 & 0.03 & \pm 0.01 & 0.09 & \pm 0.02 & 0.12 & 0.042 & 0.043 & $>10$ \\
\hline LT176 & 1.1 & \pm 0.00 & 1.2 & \pm 0.39 & 0.040 & 0.030 & 0.023 & $>10$ \\
\hline LT168 & 1.4 & \pm 0.39 & 0.03 & \pm 0.00 & 0.057 & 0.042 & 0.038 & $>10$ \\
\hline LT170 & 0.39 & \pm 0.03 & 0.03 & \pm 0.01 & 0.073 & 0.048 & 0.038 & $>10$ \\
\hline
\end{tabular}

species of approximately $15 \mathrm{kDa}$ which is expected for unglycosylated VHH (Fig. 2a). Deglycosylation of LT109 by endoglycosidase $\mathrm{H}$ treatment resulted in only this $15-\mathrm{kDa}$ species, confirming that LT109 is partially glycosylated (Fig. 2q). Densitometric comparison of bands representing glycosylated and deglycosylated LT109 revealed that about $98 \%$ of LT109 is glycosylated. A similar analysis revealed that LT156 is not glycosylated (Fig. 2a).

Deglycosylation of LT109 resulted in a fivefoldincreased $\mathrm{IC}_{75}$ in a Vero cell assay and a threefoldincreased $\mathrm{IC}_{50}$ in a GM1-LT inhibition ELISA (Table 1), indicating that $\mathrm{N}$-glycosylation of LT109 contributes to its LT-neutralizing capacity.

Enhancement of virus neutralization by glycosylation of VHHs

We next analyzed the effect of VHH glycosylation on virus neutralization. For this purpose, we used two previously isolated FMDV-binding VHHs, M180, and M200, that lack potential $N$-glycosylation sites and neutralize FMDV in vitro (Harmsen et al. 2007). These VHHs were genetically fused to a porcine IgG binding VHH, VI-12, that contains a high-mannose-type $\mathrm{N}$-glycan at position 28 (Harmsen et al. 2005a). Both yeast-produced genetic fusions (VHH2s) were also efficiently glycosylated as revealed by analysis of endoglycosidase H-treated and untreated samples (Fig. 2b). These glycosylated VHH2s neutralized FMDV at at least fourfold-lower concentrations than observed with the corresponding individual FMDV-binding VHHs and at at least 50-fold-lower concentrations than their deglycosylated counterparts (Table 2). This shows that VHH glycosylation contributes to FMDV neutralization.

\section{Discussion}

After isolating $27 \mathrm{VHHs}$ binding to $E$. coli $\mathrm{LT}$, a single yeastexpressed clone, LT109, was found to be $N$-glycosylated at a 
a

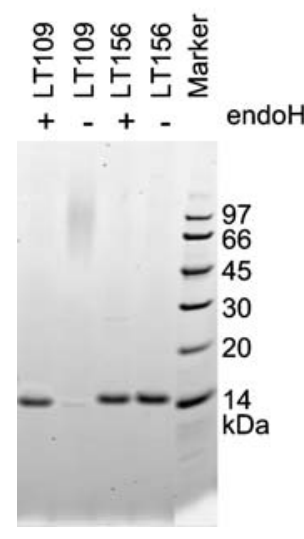

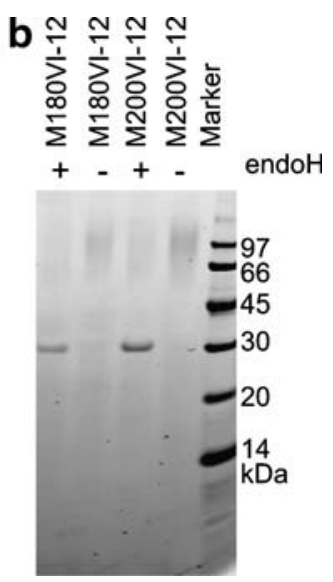

Fig. 2 Analysis of glycosylation of VHHs a and VHH2s b by SDSPAGE. Samples were either treated $(+)$ or mock-treated $(-)$ with endoglycosidase $\mathrm{H}(\mathrm{endoH})$. The molecular mass of the markers used is indicated

single site. This clone was also found to neutralize LT most efficiently, suggesting that its $N$-glycosylation contributes to toxin neutralization. This is confirmed by the at least threefold-decreased neutralization efficiency of enzymatically deglycosylated LT109. About $98 \%$ of the LT109 molecules are glycosylated. Such partial glycosylation of sites is more often observed (Kukuruzinska and Lennon 1998). The presence of some unglycosylated LT109 complicates determination of the exact contribution of $\mathrm{N}$-glycosylation to toxin neutralization since the glycosylated VHH could bind to LT with lower affinity. This is not unlikely since the glycosylation site of LT109 is located within CDR2, a region which is often directly involved in antigen binding (Muyldermans et al. 2001).

Most VHHs bound the B-subunit and their ability to neutralize LT in vitro seemed to correlate with their ability to inhibit toxin binding to the GM1 receptor, as measured by an inhibition ELISA. This is consistent with previous findings in the many studies on conventional monoclonal antibodies against LT or CT, and the view that toxin neutralization relies on inhibition of toxin receptor interac- tion (Spangler 1992; Apter et al. 1993). Since LT contains five GM1 binding sites (Sixma et al. 1992), neutralizing VHHs must inhibit multiple receptor interactions. This can be accomplished either by binding of multiple VHHs to a single LT molecule or by blocking of multiple receptor sites by a single VHH. In the latter case, an increased size of the VHH due to $N$-glycosylation is likely to increase toxin neutralization. Possibly, the glycosylation occurring close to the antigen-binding site results in more efficient blocking of toxin receptor sites as compared to glycosylation occurring more distant from the antigen-binding site. It remains to be determined whether glycosylation of $\mathrm{VHHs}$ also increases inhibition of monovalent interactions.

We also assessed the effect of VHH glycosylation on virus neutralization using two VHHs that are able to bind FMDV. These VHHs naturally lacked potential glycosylation sites. They were indirectly glycosylated by genetic fusion to another VHH that was known to be glycosylated. This successful approach could generally be applied to obtain glycosylation of VHHs. In both cases, the $\mathrm{N}$ glycosylation improved the FMDV neutralizing capacity at least fourfold. One of these VHHs, clone M200, binds to the GH-loop (Harmsen et al. 2007), which directly binds to the cellular receptor. As a result, it is unlikely that the increased neutralization relies on interference of the oligosaccharide with the GH-loop to which the VHH binds. However, each virion contains 60 GH-loop copies (Mateu and Verdaguer 2004). Possibly, the increased neutralization of the GH-loop-binding clone M200 due to $\mathrm{N}$-glycosylation results from steric hindrance of other GH-loop-receptor interactions on the virion surface.

Protein glycosylation can also contribute to protein stability after in vivo application (Sinclair and Elliott 2005). Since we studied the effect of neutralization in vitro and because non-glycosylated VHHs already have a high physicochemical stability (Van der Linden et al. 1999), it is unlikely that the decreased toxin or virus neutralization by deglycosylated VHHs results from reduced stability.

Parenteral application to mammals of proteins containing terminally mannosylated carbohydrates, such as those occur-
Table 2 Effect of VHH2 glycosylation on FMDV neutralization

\begin{tabular}{lll}
\hline VHH(2) & Endoglycosidase H treatment & FMDV neutralization $(\mathrm{mg} / \mathrm{ml})$ \\
\hline M180shVI-12 & - & 0.008 \\
M180shVI-12 & + & 1 \\
M200shVI-12 & - & 0.016 \\
M200shVI-12 & + & 1 \\
M180 & - & 0.22 \\
M200 & - & 0.059 \\
VI-12 & - & $>10^{\mathrm{a}}$ \\
VI-12 & + & $>1$ \\
\hline
\end{tabular}


ring in yeast, results in their rapid clearance in vivo due to binding to high-mannose receptors in the liver (Wright and Morrison 1994). This complicates the immunotherapeutic use of $N$-glycosylated FMDV-binding VHHs, which should be applied parenterally, but not of LT-binding VHHs, which should be delivered to the intestinal lumen by oral application. The use of recombinant yeast strains (Hamilton and Gerngross 2007) or plants (Strasser et al. 2008) that are engineered to produce proteins with human-like glycosylation for production of glycosylated VHHs could prevent rapid in vivo clearance after parenteral application.

Normally non-glycosylated VHHs can be converted to $\mathrm{N}$-glycosylated VHHs by the introduction of potential $\mathrm{N}$ glycosylation sites by site-directed mutagenesis (Sagt et al. 2000). Thus, the neutralization capacity of VHHs could possibly be further increased by obtaining glycosylation on single or even multiple sites that are located distant from the VHH antigen-binding site. Such an approach has the additional benefit of an increased yeast production level of glycosylated VHHs (Sagt et al. 2000).

Conflict of interest The authors have no conflict of interest.

Open Access This article is distributed under the terms of the Creative Commons Attribution Noncommercial License which permits any noncommercial use, distribution, and reproduction in any medium, provided the original author(s) and source are credited.

\section{References}

Apter FM, Lencer WI, Finkelstein RA, Mekalanos JJ, Neutra MR (1993) Monoclonal immunoglobulin A antibodies directed against cholera toxin prevent the toxin-induced chloride secretory response and block toxin binding to intestinal epithelial cells in vitro. Infect Immun 61:5271-5278

Cuatrecasas P (1973) Gangliosides and membrane receptors for cholera toxin. Biochemistry 12:3558-3566

Frenken LGJ, van der Linden RH, Hermans PW, Bos JW, Ruuls RC, de Geus B, Verrips CT (2000) Isolation of antigen specific llama VHH antibody fragments and their high level secretion by Saccharomyces cerevisiae. J Biotechnol 78:11-21

Gavel Y, von Heijne G (1990) Sequence differences between glycosylated and non-glycosylated Asn-X-Thr/Ser acceptor sites: implications for protein engineering. Protein Eng 3:4 $33-442$

Hamers-Casterman C, Atarhouch T, Muyldermans S, Robinson G, Hamers C, Songa EB, Bendahman N, Hamers R (1993) Naturally occurring antibodies devoid of light chains. Nature 363:446-448

Hamilton SR, Gerngross TU (2007) Glycosylation engineering in yeast: the advent of fully humanized yeast. Curr Opin Biotechnol 18:387-392

Harmsen MM, Ruuls RC, Nijman IJ, Niewold TA, Frenken LGJ, de Geus B (2000) Llama heavy-chain V regions consist of at least four distinct subfamilies revealing novel sequence features. Mol Immunol 37:579-590
Harmsen MM, Smits CB, de Geus B (2002) Stimulation of chymosin secretion by simultaneous expression with chymosin-binding llama single-domain antibody fragments in yeast. Appl Microbiol Biotechnol 60:449-454

Harmsen MM, Van Solt CB, Fijten HPD, Van Setten MC (2005a) Prolonged in vivo residence times of llama single-domain antibody fragments in pigs by binding to porcine immunoglobulins. Vaccine 23:4926-4934

Harmsen MM, van Solt CB, Hoogendoorn A, van Zijderveld FG, Niewold TA, van der Meulen J (2005b) Escherichia coli F4 fimbriae specific llama single-domain antibody fragments effectively inhibit bacterial adhesion in vitro but poorly protect against diarrhoea. Vet Microbiol 111:89-98

Harmsen MM, De Haard HJ (2007) Properties, production, and applications of camelid single-domain antibody fragments. Appl Microbiol Biotechnol 77:13-22

Harmsen MM, Van Solt CB, Fijten HPD, Van Keulen L, Rosalia RA, Weerdmeester K, Cornelissen AHM, De Bruin MGM et al (2007) Passive immunization of guinea-pigs with llama single-domain antibody fragments against foot-and-mouth disease. Vet Microbiol 120:193-206

Holmgren J (1981) Actions of cholera toxin and the prevention and treatment of cholera. Nature 292:413-417

Kukuruzinska MA, Lennon K (1998) Protein N-glycosylation: molecular genetics and functional significance. Crit Rev Oral Biol Med 9:415-448

Lefranc MP (2004) IMGT, The International ImMunoGeneTics Information System. Methods Mol Biol 248:27-49. http://imgt. cines.fr

Mateu MG, Verdaguer N (2004) Functional and structural aspects of the interaction of foot-and-mouth disease virus with antibodies. In: Sobrino F, Domingo E (eds) Foot and mouth disease. Current perspectives. Horizon, Norfolk, pp 222-260

McCafferty J, Johnson KS (1996) Construction and screening of antibody display libraries. In: Kay BK, Winter J, McCafferty J (eds) Phage display of peptides and proteins. Academic, San Diego, pp 79-111

Muyldermans S, Cambillau C, Wyns L (2001) Recognition of antigens by single-domain antibody fragments: the superfluous luxury of paired domains. Trends Biochem Sci 26:230-235

Parren PW, Burton DR (2001) The antiviral activity of antibodies in vitro and in vivo. Adv Immunol 77:195-262

Saerens D, Ghassabeh GH, Muyldermans S (2008) Single-domain antibodies as building blocks for novel therapeutics. Curr Opin Pharmacol 8:1-9

Sagt CM, Kleizen B, Verwaal R, de Jong MD, Muller WH, Smits A, Visser C, Boonstra $\mathrm{J}$ et al (2000) Introduction of an $\mathrm{N}$ glycosylation site increases secretion of heterologous proteins in yeasts. Appl Environ Microbiol 66:4940-4944

Sinclair AM, Elliott S (2005) Glycoengineering: the effect of glycosylation on the properties of therapeutic proteins. J Pharm Sci 94:1626-1635

Sixma TK, Pronk SE, Kalk KH, van Zanten BA, Berghuis AM, Hol WG (1992) Lactose binding to heat-labile enterotoxin revealed by X-ray crystallography. Nature 355:561-564

Spangler BD (1992) Structure and function of cholera toxin and the related Escherichia coli heat-labile enterotoxin. Microbiol Rev 56:622-647

Speirs JI, Stavric S, Konowalchuk J (1977) Assay of Escherichia coli heat-labile enterotoxin with Vero cells. Infect Immun 16: $617-622$

Strasser R, Stadlmann J, Schahs M, Stiegler G, Quendler H, Mach L, Glossl J, Weterings $\mathrm{K}$ et al (2008) Generation of glycoengineered Nicotiana benthamiana for the production of monoclonal antibodies with a homogeneous human-like $N$-glycan structure. Plant Biotechnol J 6:392-402 
Van der Linden RH, Frenken LG, De Geus B, Harmsen MM, Ruuls RC, Stok W, de Ron L, Wilson S et al (1999) Comparison of physical chemical properties of llama VHH antibody fragments and mouse monoclonal antibodies. Biochim Biophys Acta 1431:37-46

Van der Vaart JM (2002) Expression of VHH antibody fragments in Saccharomyces cerevisiae. In: O'Brien PM, Aitken R (eds)
Methods in molecular biology, Vol. 178, antibody phage display: methods and protocols. Humana, Totowa, NJ, pp 359-366

Wright A, Morrison SL (1994) Effect of altered CH2-associated carbohydrate structure on the functional properties and in vivo fate of chimeric mouse-human immunoglobulin G1. J Exp Med 180:1087-1096 